\title{
Grain reserves and food security in the Middle East and North Africa
}

\author{
Brian Wright • Carlo Cafiero
}

Received: 3 September 2010 / Accepted: 30 December 2010 / Published online: 10 February 2011

(C) The Author(s) 2011. This article is published with open access at Springerlink.com

\begin{abstract}
Aggregate stocks of major grains declined to minimal feasible levels in 2007-2008, due to high global income growth and biofuel mandates. Given these minimal stocks, prices were very sensitive to shocks, such as the Australian drought, and biofuel demand boosts due to the oil price spike. The effects of these shocks were magnified by a sequence of trade restrictions by key exporters to protect vulnerable consumers. Beginning in the 'thin' global rice market in the fall of 2007, these turned market anxiety into panic. Recognizing the unreliability of imports, vulnerable countries, including some in the Middle East and North Africa (MENA), are now considering investing in strategic reserves, pursuing self sufficiency and acquiring foreign land to ensure grain supplies for domestic consumption. The associated expense and negative incentive effects on national reserves may be acceptable if they have quantitative targets related to the needs of the most vulnerable,
\end{abstract}

Funding for this paper was provided by the International Bank for Reconstruction and Development/The World Bank. The findings, interpretations, and conclusions expressed do not necessarily reflect the view of the Executive Directors of The World Bank or the governments they represent. We thank Juilan Lampietti for crucial information on the MENA region, advice and support, and Nick Magnan for facilitating our research in many ways. Material in this paper draws on related work presented at the World Grain Forum, St Petersburg, Russia, June 6-7, 2009, and contained in B. Wright, "International Grain Reserves And Other Instruments to Address Volatility in Grain Markets," World Bank Research Observer, forthcoming.

\footnotetext{
B. Wright $(\bowtie)$

Department of Agricultural and Resource Economics, 207 Giannini Hall, University of California,

Berkeley, CA 94720-3310, USA

e-mail: bwright@berkeley.edu

C. Cafiero

Department of Agricultural Economics and Policy,

University of Naples Federico II,

Via Universita' 96,

80055 Portici, NA, Italy
}

for distribution only in emergencies. In many MENA countries, heavy subsidies on grain consumption for both rich and poor reduce the stabilizing response of consumption to price, and increase reserves needed to ensure food security. Accumulation of stocks is a more efficient strategy than pursuit of self-sufficiency in most MENA countries, as they have no comparative advantage in expanding agriculture, given restricted water supplies. Acquisition of foreign lands leaves food supplies exposed to sovereign risk and other supply chain problems beyond importers' control. MENA countries could cooperate and so smooth much of the risk posed by fluctuations in their own harvests.

Keywords Grain reserves · Food security $\cdot$ Middle East and North Africa $\cdot$ Supply risk

\section{Introduction}

The price increases of many consumption commodities during 2007-2008, including the major grains, shocked consumers and governments in many regions. The prospect of continuing high grain market volatility is particularly threatening to countries in the Middle East and North Africa (MENA) given their high levels of cereal consumption and heavy dependence on imports (World Bank 2009). Up to 35\% of the region's calorie consumption is from wheat, and the region is collectively a net importer of 58.1 million tonnes of cereal, making it the largest net importing region in the world. Import dependence is projected to increase from $56 \%$ in 2000 to $63 \%$ in 2030, leaving the region even more vulnerable to high and volatile international market prices.

Urban consumers, alarmed by the market turmoil concerning their staple foods, participated in protests, often violent, that peaked at about the time world grain prices peaked in mid-2008. Some demonstrations threatened to destabilize their governments (e.g. Slayton 2009), and in 
response, many nations adopted short-term policies to reduce the effects of rising world prices on domestic consumers. Though perhaps rational within each country, the collective effects of these policies exacerbated international price volatility, and often penalized the domestic farmers and traders whose supplies to the market prevented more serious shortages. To make matters worse, importers' concerns about food market access were heightened by news that key rice exporters were discussing an export cartel, and that Argentina's proposal to tax wheat exports had disrupted that country's role as a key exporter. Many importers, including some MENA countries (e.g. Morocco and Saudi Arabia) exacerbated competition for scarce imports by removing tariffs or subsidizing imports of grains (Hater 2008).

Grain prices have receded significantly since 2008 , but remain more volatile than earlier in the decade, and food security remains a major policy problem in the MENA region. The policy focus has switched from short-term tactics for crisis management to strategies to manage the effects of market fluctuations on consumers at acceptable cost. Increasing grain reserves has figured prominently in international discussions, with proposals made for international reserves combined with what advocates describe as 'virtual reserves' controlled via commodity futures and options trading. Special regional emergency reserves have been proposed for countries concerned about possible lack of access to the global trade. Some observers have recommended regulation of commodity futures trading by non-commercial investors, while Ethiopia is supporting the establishment of a new futures exchange as part of their grain market policy (Jopson and Blas 2008). Many have pressed for reducing subsidies or mandates for biofuel production on the grounds that such policies threaten food markets' stability. Several MENA countries (and others) have taken steps to secure land in Africa and elsewhere to produce grains to augment domestic supplies.

In this context, the main objective of this paper is to provide government officials, representatives of civil society, and officials of international organizations involved in food security with an overview of the potential roles and problems associated with using physical storage and related policies as means of enhancing food security. The paper discusses how MENA countries can use storage to address their food security related needs and challenges; it shows how properly managed storage can effectively integrate international trade and other domestic policies in achieving acceptable food security. In particular, the paper concludes that storage can and should be used to reduce the risks of food shortages. This avoids the unsustainable costs associated with self-sufficiency in food production by countries with limited agricultural potential due to water scarcity and other resource constraints, while also mitigating effects of volatile international grain markets. The paper puts into perspective the many options currently discussed by
MENA policy makers, who rightly consider their citizens' food security an important national goal. The paper should help countries to achieve greater food security by illuminating the costs and benefits of the alternatives.

\section{Strategy and policy options for enhanced food security}

What is the evidence on aggregate food price behavior?

Aggregate food price has been less variable over recent years than many of its components, particularly food grains. ${ }^{1}$ In 2005 the FAO food price index (Fig. 1) showed a modestly rising trend 20\% higher than the 1998-2000 average. Prices accelerated in 2006, and by October were climbing sharply until the summer of 2008, when the index exceeded twice its 2005 level; by late summer, it had fallen far from the peak, but remained much higher than in 2000. However, this aggregate food price index understates the price fluctuations of the major food grains that attracted most attention.

For a longer view, the real price of wheat in the USA trended downward for decades (Fig. 2), reflecting yields that generally outpaced demand growth. Along their downward paths, prices generally fluctuate moderately within a reasonably defined range. However, episodes of steeply rising prices, followed by precipitous falls, are prominent features. The price series are asymmetric, there being no equally prominent troughs to match spikes, and when the price is relatively low the probability of a sudden fall is negligible. These features are characteristic of commodities generally and, relative to other spikes in the figures, those of recent years are not particularly high, when properly deflated.

The overall downward trend in prices is principally due to the remarkable success of plant breeders and farmers in continually developing and adopting new crop varieties with increased yields, and to the development of cheap and plentiful supplies of fertilizers and other inputs.

Increases in world consumption of the major grains have occurred even as the scope for expanding cultivated area has greatly diminished in most countries (Fig. 3). Note also the recent surge in diversion of maize to biofuel uses.

These aggregate figures mask great regional variation in prices and consumption, but the globalization of markets and reduction in shipping costs offer great opportunities for smoothing local fluctuations. Figure 4 shows wheat

\footnotetext{
${ }^{1}$ Although we focus on aggregate numbers, it is important to note that they mask large variation between countries, due to trade barriers, domestic price and tax policies, and transport costs. As trade barriers, tariffs and transport costs have changed abruptly, the scope of various international markets has also been redefined. Furthermore, consumers in large or landlocked countries often face widely varying prices. For many, the international prices and global policies discussed here might have little relevance (see De Hoyos and Medvedev 2009).
} 
Fig. 1 FAO food price index (1990-2009). Source: FAO. Note the deflated food price index is calculated by deflating the FAO monthly food price index using the monthly US $\mathrm{CPI}$, and then normalized such that $2002-2004=100$

\section{Deflated Monthly Food Price Index}

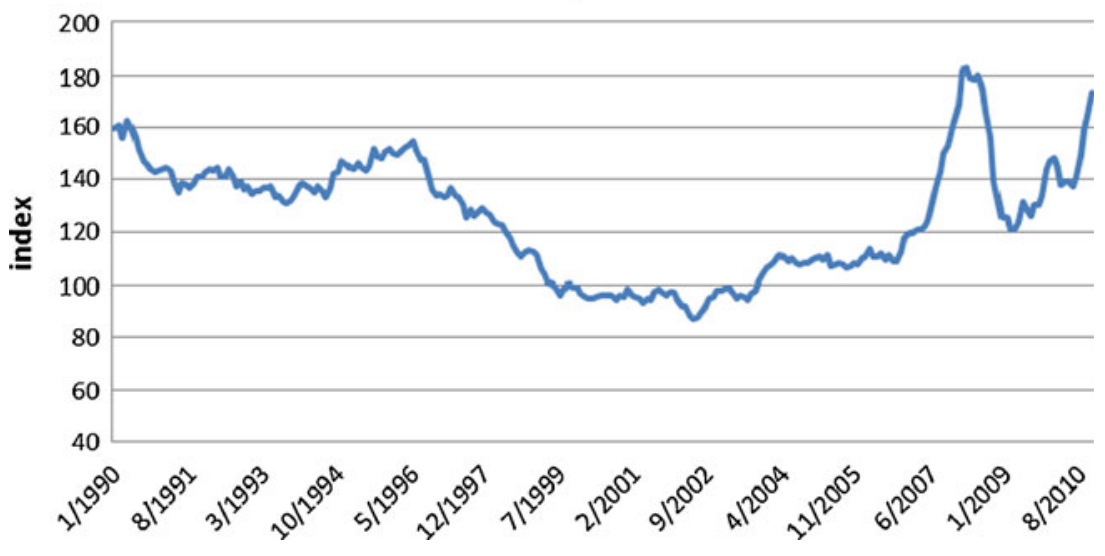

production in individual countries and in the whole MENA region. Pooling the entire regional output variation and sharing it proportionally would considerably stabilize wheat supplies, especially for Morocco, Iraq, Saudi Arabia and Tunisia. However, they would still need to import large portions of their grain supplies to feed their populations.

The increased demand for grain for human consumption has been driven mainly by increased global population, although the rate of increase has begun to slow. Only in poorer countries is increased income an important driver of grain consumption per capita, which is naturally limited by human stomach capacity. For grains used for animal feed, the trend towards increased consumption has been greater, because human consumption of animal products continues to rise with income long after minimum calorie requirements are satisfied. Use of maize as an animal feed has boosted its demand beyond the expectations based on its use as a human staple. Animal feed accounts for a smaller but significant share of wheat production, notably in Europe. Rice is used predominantly as a food. There is substantial agreement about the drivers of these long-term trends in grain consumption and prices; however, opinions differ on the causes of recent grain price volatility.

What caused recent grain price fluctuations?

A consensus is emerging among economists concerning the contributions of different factors to the recent market volatility for grains. Predictable disturbances can cause price trends, but not spikes, unless normal market responses are somehow constrained ${ }^{2}$ - spikes are generated by surprises. Thus, the recent rapid increases in income in China

\footnotetext{
${ }^{2}$ The large increase in crude oil price in 2008, for example, was predicted by the huge contango in the futures market, but lack of storage capacity precluded the inter-temporal arbitrage that would normally smooth the price response.
}

and India have increased global demand for food and feed grains, but these increases, sustained for several years, were only surprising in their continuation into 2008. Similarly, reductions in the rate of yield increases in rice and wheat could have contributed to a tighter market, but as mediumterm phenomena related to global neglect of crop research, they were hardly surprises. For detailed discussions see Abbott et al. (2008, 2009), Mitchell (2008), Timmer (2008) and Gilbert (2008). Factors such as the unprecedented extension of the Australian drought, other regional production problems, the possible effects of global warming, and exchange rate movements were much less predictable. However, their influence was not sufficient to explain most price spikes of 2007-2008.

Other market disturbances, which it was not possible to predict before 2007, were global in influence and deserve particular attention: the changes in biofuel policies and demand, and price spikes of fertilizers and fuel. As all relate directly to recent price spikes in the petroleum market, they merit special consideration by a regional group which includes many of the world's major petroleum exporters.

\section{Biofuel demand}

The conversion of oilseeds into biodiesel in Europe, the USA and elsewhere; of sugar into ethanol in Brazil; and of maize into ethanol in the USA, link events in the world energy markets to food market behavior in a qualitatively new way. ${ }^{3}$

In the USA, the diversion of maize and soybean to biofuel approaches $30 \%$ and $20 \%$, respectively. This will further increase under current policies using subsidies and

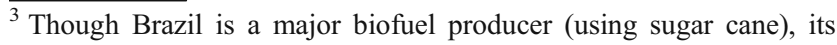
production has apparently not diverted large areas from grain production. Recent sugar market volatility, however, has focused attention on the food market implications of Brazilian reliance on the sugar-derived ethanol.
} 
Fig. 2 Real price of wheat in the USA (1950-2009)

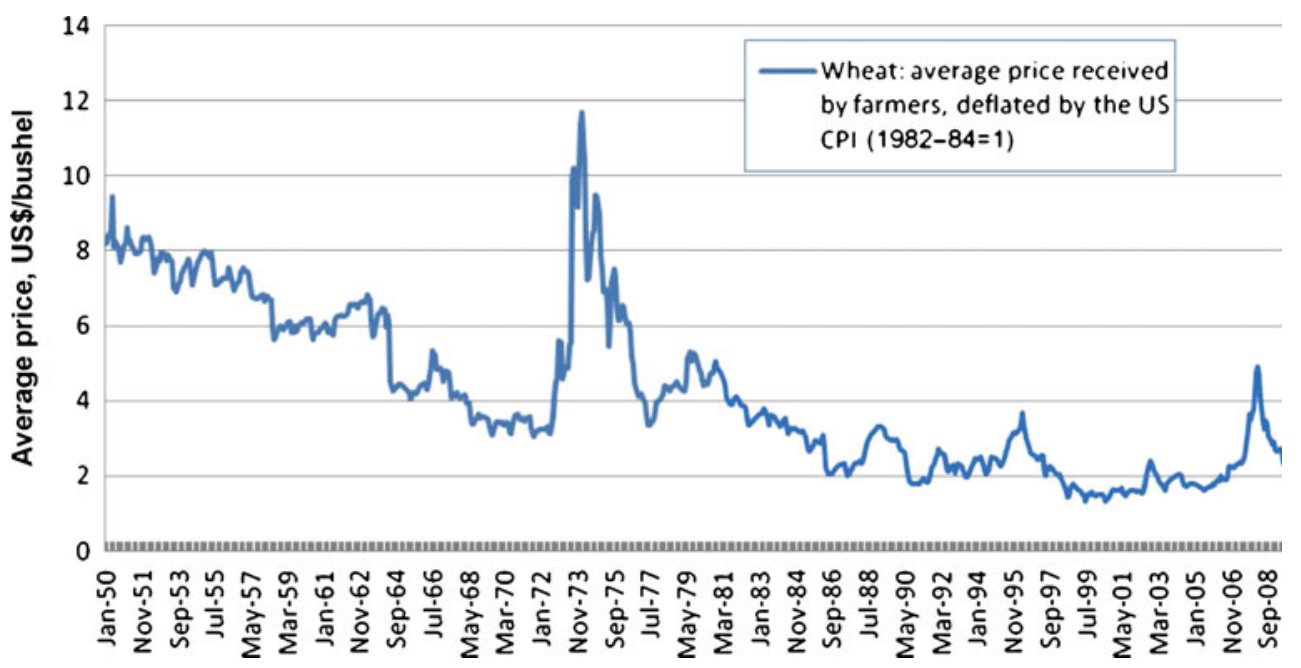

mandates, as well as protection from competition from more efficient Brazilian sugar-derived ethanol. The southern corn leaf blight infestation of 1971 cut maize supply in the USA by only half the percentage currently diverted to biofuels; however, it was a very serious shock that directed attention to the USA's food security. Furthermore, the mandates for diversion of US maize for biofuel are expected to increase and have much more serious implications for supplies of maize for feed and food than an equivalent yield drop due to blight which was controlled relatively quickly by substituting genotypes that were resistant.

As existing government mandates for the use of grains, sugar and oilseeds were viewed as solid policy commitments, strong biofuel demand was clearly foreseeable by 2006-before prices took off. However, unanticipated oil price jumps must have encouraged upward revisions in the expected growth of biofuel-related demand for grains and oilseeds, as did upward revisions in the mandates in the
USA. Furthermore, the diversions were too great to be made up in the short run by increased yields. They must have had large effects on the decreases in grain stocks, and the steady price increases in the years immediately preceding 2007-2008.

Wheat and other food grains were diverted to animal feed to substitute for maize diverted to ethanol and oilseeds diverted to biodiesel. Consumers increased rice demand, to replace the wheat used for feed. Biofuel demands and surges in meat demand caused by rising incomes also affected food grain markets less directly by diverting inputs from food grains toward feed and biofuel. Some rice land may have been diverted to produce maize or soybean, but it is unlikely this greatly affected overall rice production. The best rice land is ill-suited to corn or soybean in the temperate zones where much of the world's maize and soybean are grown. However, on Asian croplands where two or three crops are possible annually, wheat can replace
Fig. 3 Global consumption of grains. Source World Bank

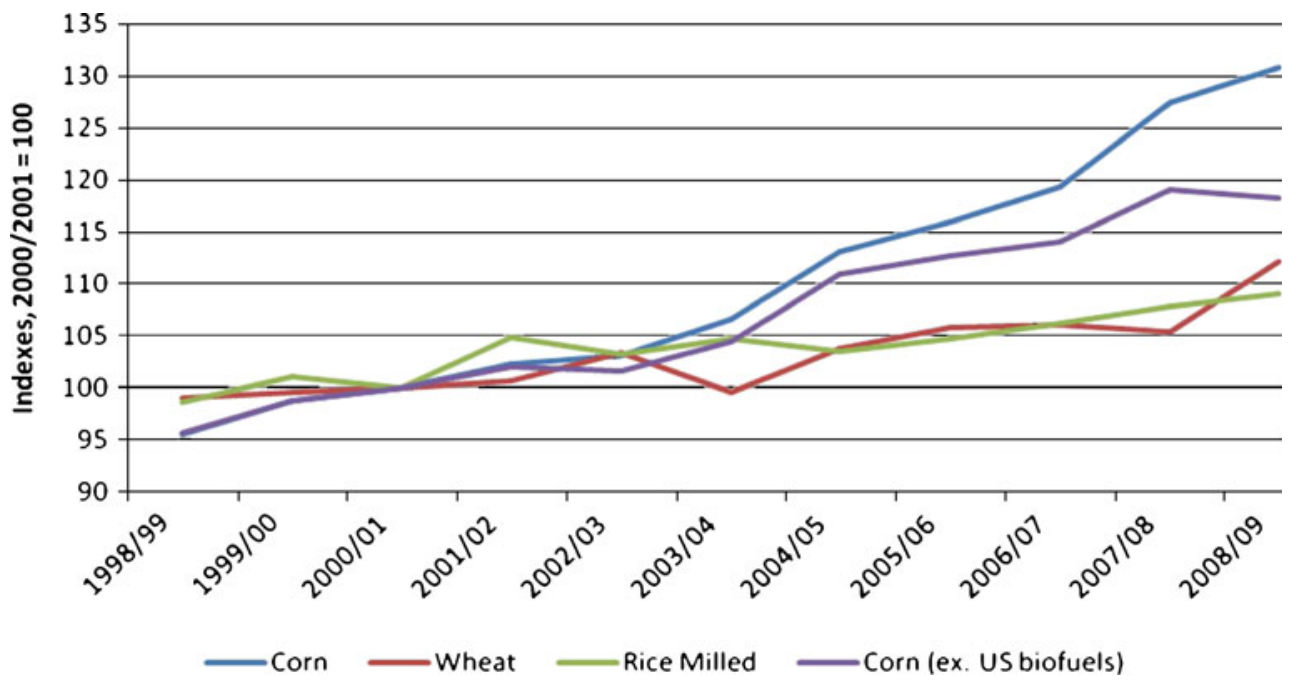


Fig. 4 Wheat production in the MENA region (million tonnes, 1979-2009). For each series, figure in parentheses shows coefficient of variation (after de-trending) of deviations from linear trend. Quantities relative to entire MENA region are shown on right axis

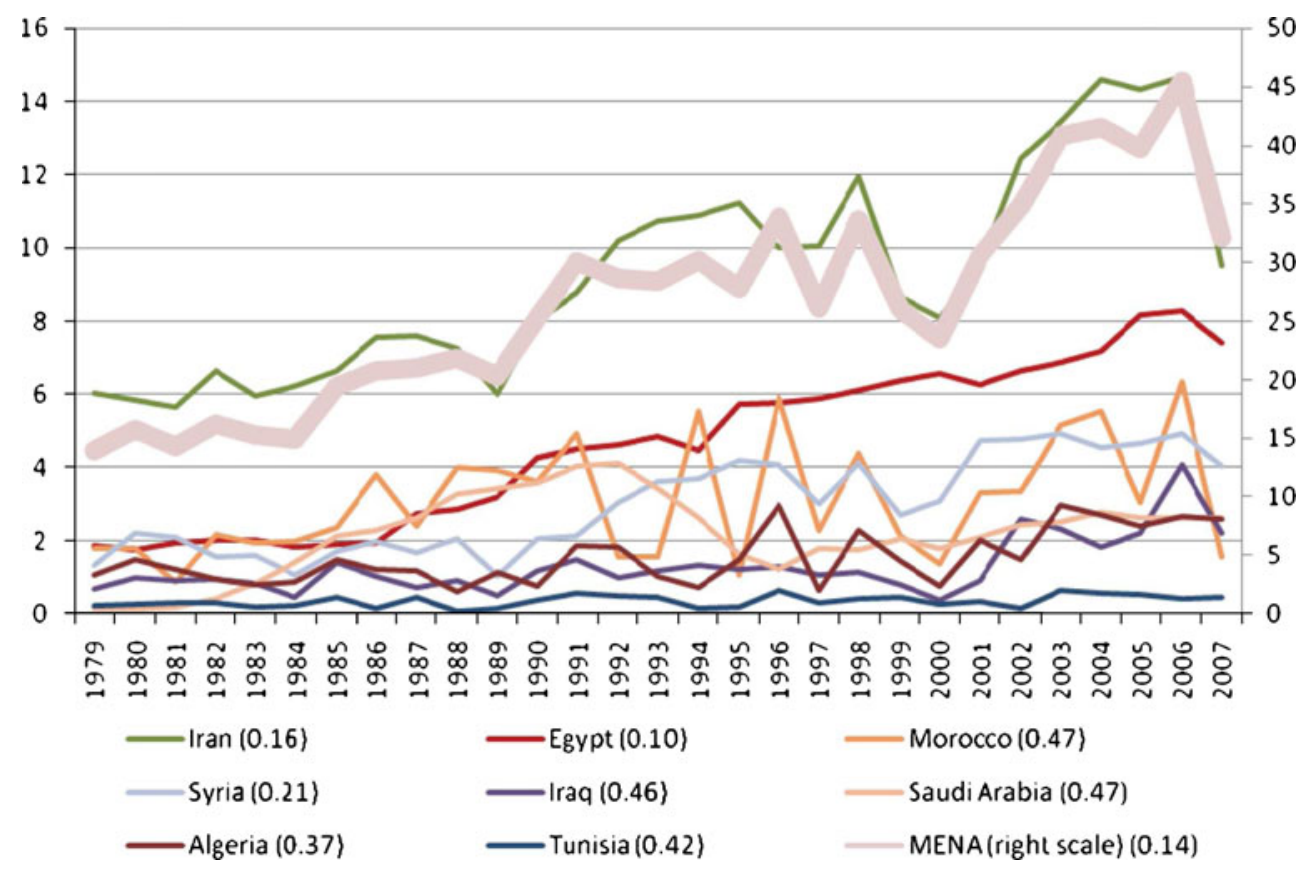

rice as a dry-season, irrigated crop when its relative price increases.

\section{Prices of fertilizers and fuels}

Worldwide adoption of modern high-yielding plant varieties and lower opportunities for expansion of cultivated area has increased fertilizer demand. Prices of some fertilizers rose faster than any other agricultural commodity price in 2007 2008 , reflecting short-term supply constraints, energy costs and transport costs. Although some farmers and ethanol producers have blamed fertilizer and oil prices for grain price spikes, the evidence is not convincing. Grain price rises associated with previous harvests preceded fertilizer price movements, not vice versa.

Crude oil is an important input into modern agriculture, both directly and indirectly. Its price is virtually independent of disturbances in the grain markets. Crude oil prices have been very high recently, but there was no large effect on acreage or yield even in countries that use petroleum intensively in production. Farm prices in the USA rose dramatically as grain, fuel and fertilizer prices rose, indicating the net effect on farmers' profits and incentives was positive and large. In contrast, unpredictable changes in petroleum prices affected grain demand, since jumps in petroleum prices now not only affect farmers' costs, but also shift demand for the grain they produce via increased biofuel demand. This is a new phenomenon. When ethanol production exceeds mandated levels, marginal fuel price changes increase total demand for grains even as they increase input costs.

Pursuing this line of argument, a reasonable expectation might be that income growth and biofuel demand should have less influence on the price volatility of rice relative to maize and wheat. Yet the price spike was the highest for rice in 2008, indicating another significant contributor to chaos in the world grain markets - panic in the rice trade.

\section{Panic in vulnerable markets}

On 9 October 2007, the Indian Government banned exports of rice other than basmati, and increased rice availability to its consumers to reduce their concerns about inflation, and the adequacy of staple food supplies after a poor wheat harvest. The rice price outside of India began to rise (Fig. 5) - a problem with wheat supply thus triggered a sequence of decisions by other major exporters leading to the crisis in rice prices and market access (Slayton 2009).

As reports of production problems in other countries proliferated, governments of grain exporting countries were pressured by their urban consumers to reduce grain prices. These pressures temporarily outweighed the interests of producers and traders in selling to the highest bidder. One by one, rice exporters imposed their own export restrictions, including in March 2008, Viet Nam, an important supplier. ${ }^{4}$ China, itself adequately supplied, did not make its substantial grain stocks internationally available as a supplier of last resort, as it had done earlier in the decade. Instead it taxed wheat and rice exports. Other countries also imposed export controls or taxes on wheat or maize

\footnotetext{
${ }^{4}$ Viet Nam announced a ban on new sales in July 2007 (Slayton 2009).
}




Fig. 5 Thai rice price and the Indian export ban. Indicative price based on weekly surveys of export transactions, government standard fob Bangkok. Source: World Bank Development Prospects Group, and Mitchell (2008)

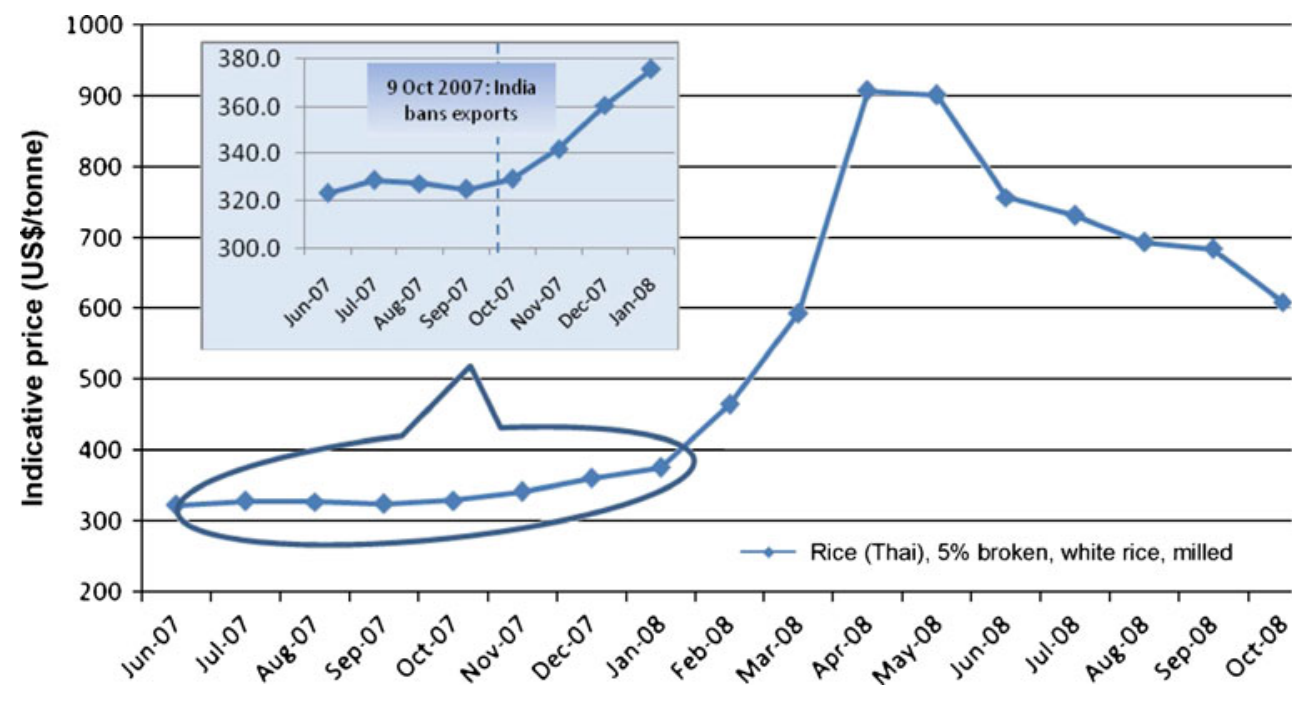

exports; e.g. Argentina, South Africa, and the MENA countries, Egypt, Syria, Iraq and Yemen (World Bank 2009; Yemtsov 2008).

Countries dependent on imports of staple foods became increasingly anxious to secure supplies. Ultimately, only Thailand and the USA remained in the market as exporters. Many countries, including Morocco, Saudi Arabia, India and China, reduced their tariffs or taxes on imports, which reduced domestic prices relative to world prices, but also contributed to increasing world prices. One discouraging example of inadequate international cooperation was the failure to negotiate timely sale of Japanese rice stocks (imported to comply with WTO mandates, and never destined for domestic consumption) to desperate international importers (Timmer 2008).

This episode highlighted the strong substitution, at the margin, between the three major grains. Indeed, the market for the major grains can be considered as a market for grain calories (Bobenrieth and Wright 2009), ${ }^{5}$ and so reliance of MENA countries on wheat is no insulation from disturbances in other grain markets. They must recognize that shocks in demand for maize for biofuels, for example, will have a relative impact on international wheat prices and availability comparable to the impacts on the maize markets. Following the causal chain further, OPEC-induced shocks to oil supply will likely affect the wheat import markets of OPEC countries.

Reviews of grain price volatility during recent years have allocated percentage shares of responsibility to a set of factors - a sensible approach if these factors had a linear cumulative effect on food price volatility; however, the effect is highly nonlinear. When supplies are already tight, another unexpected small supply reduction or new market

\footnotetext{
${ }^{5}$ Roberts and Schlenker (2009) go further, and include soybean as a fourth source of aggregate calories.
}

order can become the 'straw that breaks the camel's back' and cause a sharp price spike. This nonlinearity merits attention, as it is a key to understanding recent market events and constructing appropriate policy responses.

The economics of storage arbitrage determines the highly nonlinear relationship between grain prices and available supply, and aids evaluation of claims that other factors are the key drivers of market volatility. To understand the nonlinearity of the price-supply relationship, it is necessary to grasp some fundamental features of grain storage as an economic activity. The theoretical models separate demand for consumption from implicit demand for storage, under specific assumptions on the competitive structure of the storage industry. Once the inter-temporal price smoothing potential ensured by storage management is understood, policy analysts may be better able to value the alternative policy interventions to increase the effectiveness of storage management in enhancing food security.

\section{The economics of storage}

The effects of storage on the consumption and price of grains are illustrated in Fig. 6. The annual harvest in year $t$, $h_{t}$, is random, reflecting the influences of weather and other disturbances on production. Total demand is the horizontal sum of the demand for consumption in the current period, $c_{t}$; and the demand for grain stocks, $x_{t}$, to carry forward for later consumption. ${ }^{6}$ Consumption responds to price according to the downward-sloped market demand function $P\left(c_{t}\right)$. Stocks $x_{t}$ cannot be negative.

In storage arbitrage, regardless of the economic setting (monopoly, competition, state control of resource allocations), two accounting relations hold: available supply, $A_{t}$,

\footnotetext{
${ }^{6}$ Essential working stocks and deterioration of stocks, which do not change as prices change, are ignored here.
} 
Fig. 6 The role of stocks in buffering shocks

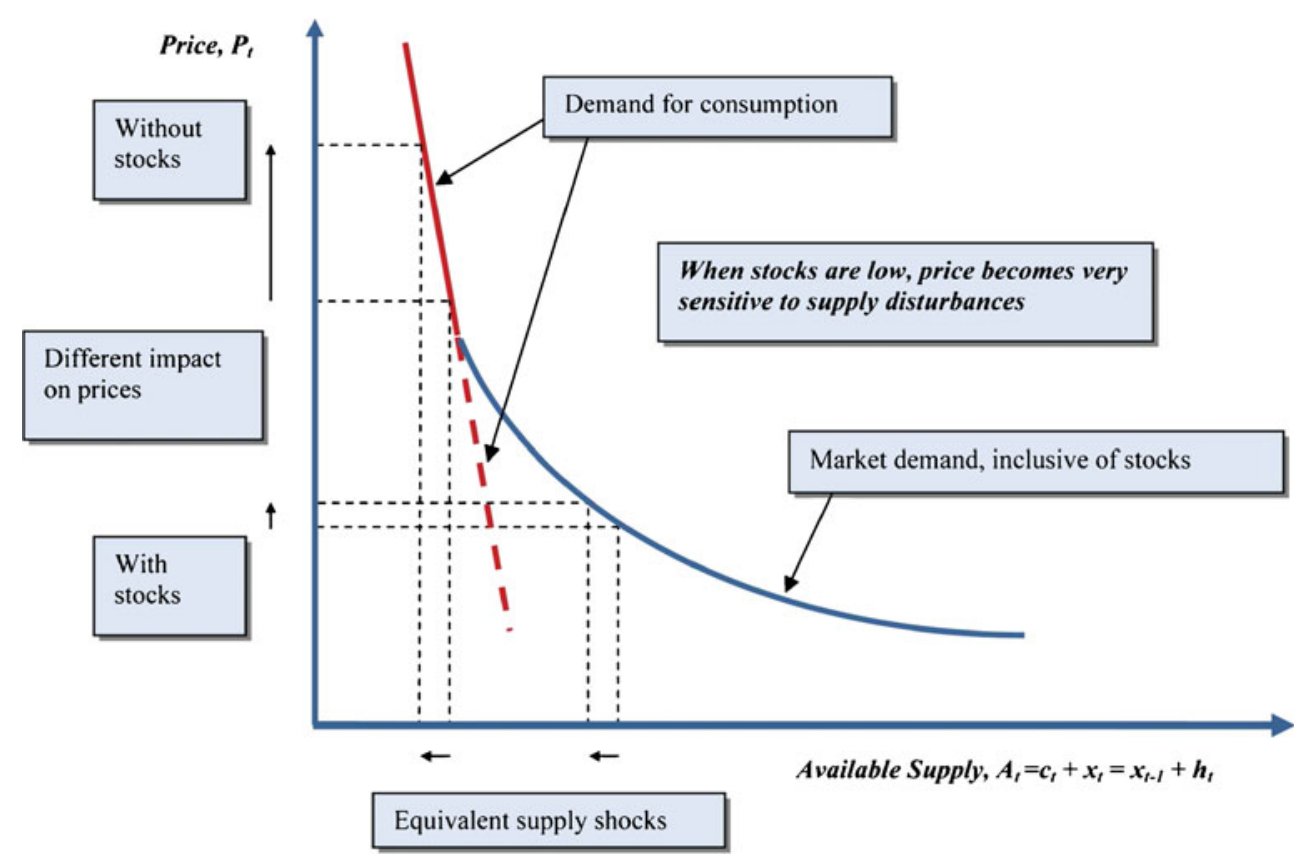

is the sum of the harvest, $h_{t}$, and stocks carried in from the previous year, $x_{t}$; and consumption is the difference between available supply and the stocks carried out. Profit-maximizing storage units hold positive stocks only if they expect returns to cover costs. If storage units are competitive, the current price of a unit stored must be expected to rise at a rate that covers the cost of storage and the interest charge on the value of the unit stored.

Given available supply, $A_{t}$, storage units carry stocks $x_{t}$ from year $t$ to year $t+1$ following a version of 'buy low, sell high'. Where the consumption demand is a downward sloping straight line (e.g. Fig. 6), if the price is sufficiently high, carried-over stocks are zero. When the price is high and no stocks remain, those who consume grains (e.g. rice, wheat or maize) as staples are willing to forego other expenditures (including health and education) to continue to eat their grain, so the consumption demand is very steep and price inelastic. Large changes in price result as consumption adjusts to the full effects of a supply shock; e.g. in 1972-1973, a reduction in world wheat production of $<2 \%$, when stocks were almost negligible, caused the annual price to more than double (Fig. 2). When stocks are high, a similar supply shock would have a far smaller effect on price (Fig. 6).

By acquiring stocks when the price is low, storage units can reduce the rise in consumption and thus cushion the associated fall in price. The disposal of stocks when supplies become scarcer reduces the severity of price spikes. If the supply of speculative capital is sufficient, storage can eliminate negative price spikes, but can smooth positive spikes only as long as stocks are available. When stocks run out, aggregate use must match a virtually fixed supply in the short term. Less grain goes to feed animals and the poorest consumers reduce their calorie consumption, resulting in malnutrition, hunger or even death.

If producers can respond to incentives with a one-year lag, that response is very stabilizing for consumption and price. If, for example, an irrigation system which has been shut down to save scarce 'fossil' water can be maintained in usable condition, it could be an emergency production reserve to stabilize consumption during severe shortage, without the high capital cost of holding emergency stocks to ensure a similar level of security.

In such markets, measuring both consumption and stocks (including stocks held by consumers) is very difficult (thus grain statistics refer to 'disappearance' rather than consumption), and complicates food policy directed at ensuring minimum consumption for all during shortages. Also, a common feature of all such physical storage activities is that, from a global viewpoint, aggregate stocks are constrained to be non-negative (even if there are conditions by which further release of stock would be profitable, because if current stocks are zero, it is impossible to 'borrow from the future'). This fact makes modeling storage behavior particularly challenging, and thus estimating market behavior based on available data is very difficult. ${ }^{7}$

\section{How global storage affects world grain markets}

To interpret the behavior of grain market prices, and identify the causes of high volatility, it is crucial to

\footnotetext{
${ }^{7}$ For estimates of storage and consumption behavior in markets for some major commodities see Cafiero et al. (2009).
} 
understand how storage behavior affects the relation between prices and available supplies of grain. The series of annual stocks-to-use ratios and annual real price indexes for wheat, reveals that the wheat price spikes in the 1970s, 1995-1996, and in 2007-2008 occurred when world stockto-use ratios were low (Fig. 7). For the market to function effectively, a virtually irreducible minimum amount of grain must be held in the system, to transport, market and process grains. For example, no matter how urgent the present demand for grain, some must be held on docks during ship loading/unloading, and elsewhere in the supply chain. Stocks data are notoriously imprecise, and minimum working stocks are about $20 \%$ of use. ${ }^{8}$ Comparison of two series (Fig. 7) shows that stocks are very unresponsive to price at these minimum levels. A similar comparison for maize would reveal the same phenomenon - spikes in price when stock-to-use ratios were low.

Another important feature of these grains is that the marginal cost of storage per period, including physical protection, insurance and spoilage, is usually modest. The assumption of constant unit costs is reasonable and a good approximation in regions where humidity is low, modern infrastructure is available, and deterioration unimportant, but not in many hot and humid environments (Paul 1970). The main cost of storing grains is usually the cost of capital invested in accumulating stocks. Increases in grain stocks are not generally limited by storage capacity. The storage of grain is profitable only if the value of the grain when released exceeds the sum of the storage cost and interest on the capital.

\section{Why public policies are needed to achieve optimal grain supplies}

In modern capitalist economies, an undistorted free market might be expected to equate the value of grain used for current consumption with the value of grain stored for the future (placed in storage). However, there are two serious problems with total reliance on private storage for national food supplies: in a free market, only those with necessary resources or 'entitlements' can acquire food, and the destitute may starve with no affect on prices; and in a food emergency, as experienced in many countries in 2008, there is a tendency to identify scapegoats for high prices or scarce supplies. Governments are pressured by politically

\footnotetext{
${ }^{8}$ Above minimum stocks, small additional fractions of stocks are placed on the market only when the incentive is high, because they are in relatively inaccessible locations or perform valuable roles in keeping the system operating efficiently. These stocks are ignored here, since they have a minor role in determining price volatility (Bobenrieth et al. 2004).
}

powerful consumers to force traders who have accumulated grain to surrender stocks to the government or directly to consumers, often without compensation, and/or to limit 'speculation' in grain markets. Sometimes these so-called 'hoarders' are also penalized. At such times, it is often forgotten that if the next crop fails, the 'hoarders' might be the sole source of supply, and speculators the key source of funds for investment. In the USA for example, long-run speculators whose futures positions provide the incentive for storage by short-hedgers, are currently the subject of much criticism, despite lack of evidence of excessive stocks.

Anticipation of such treatment discourages private storage in times of plenty, for distribution at a high price in time of need. Government commitments not to confiscate stocks (or otherwise penalize hoarders) in emergencies are not credible. Hence, governments often choose to supplement private storage with publicly acquired stocks or storage subsidies (and even if the government manages all market stocks, consumers inevitably store some domestic supplies). When public stocks are released to consumers they will have some negative effect on prices (although targeted food distribution programs to those with no money at all have minimal impact on market equilibria). Anticipation of this price effect reduces private storage incentives. Hence, it is natural to expect that governments will intervene actively when supplies are plentiful to increase grain stocks and ensure supplies for the needy and/or stabilize the market (Wright and Williams 1982; Williams and Wright 1991). Such a government role is common in MENA countries, where since ancient times, leaders have recognized the state's responsibility to ensure adequate domestic availability of staple foods, and have used public stocks of grain to this end.

\section{Traditional price-stabilization policies}

International agreements involving commodities (including rubber, cocoa and tin) have often combined an acquisition price at which the commodity is purchased from the market and stored, with a higher 'ceiling' or 'release' price, at which stocks are made available for sale by the stabilization authority. This is called a 'price band' scheme. If the ceiling price equals the acquisition price, this is a simpler 'price floor' scheme, keeping the price at the floor until stocks are sold out, or all cash for purchases has been expended. In the past, prominent economists have advocated price stabilization in a band between floor and ceiling prices to reduce 'booms and busts' typical of commodity prices (Keynes 1942; Houthakker 1967; Newbery and Stiglitz 1981).

A strong intuition is that such a program maintains price around the middle of the band if the band is judiciously chosen; however, advances in computing and dynamic 
Fig. 7 World stocks-to-use ratio and world price index for wheat. Sources: USDA for stocks-to-use ratio, World Bank for price index (calendar year average of monthly figures reported for US No. 2 Hard Winter Wheat, fob at US Gulf ports)

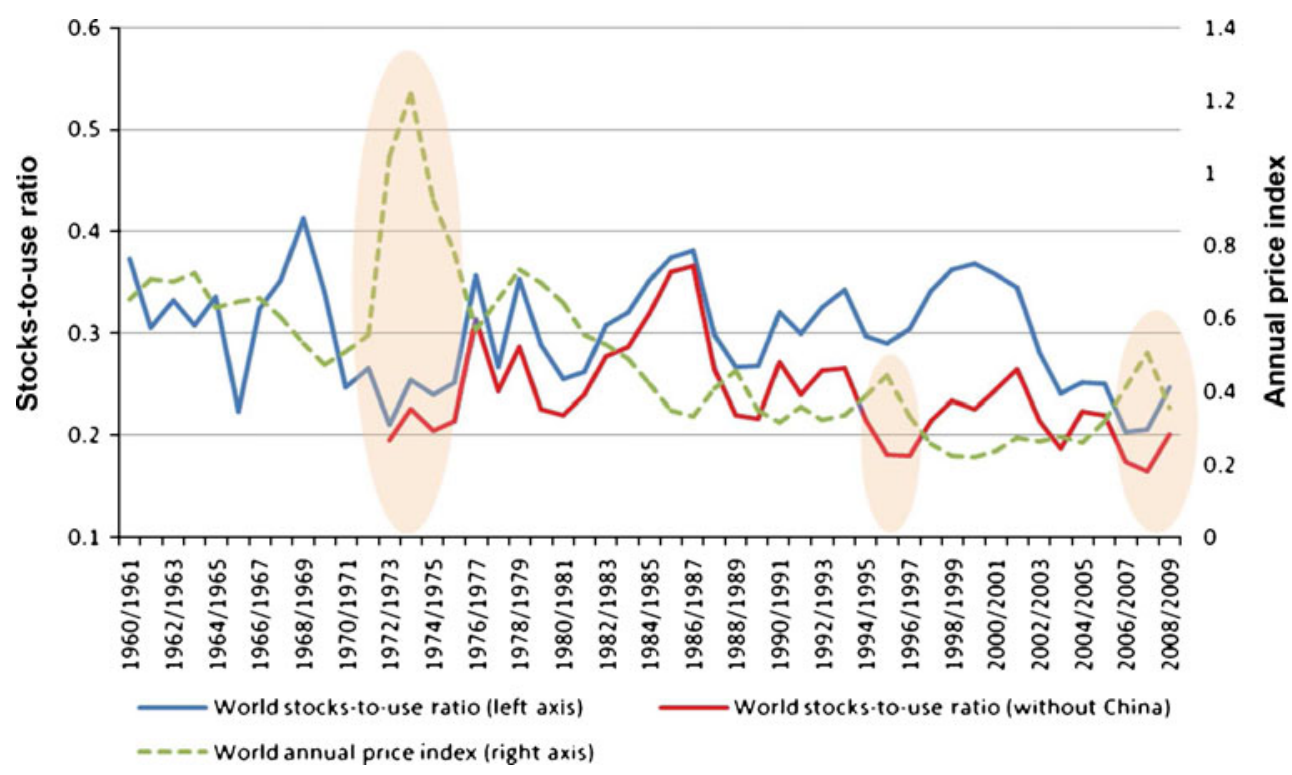

programming show this is not true. ${ }^{9}$ Williams and Wright (1991) show examples with little probability of price between the mid-point of the band and the top. Most often, the market appears to be 'challenging' either the floor or the ceiling price. An enforced price-ceiling discourages production and private storage, and increases price volatility (relative to a market with only private storage) as the latter approaches the ceiling. However, sales from the public stockpile at the ceiling markedly reduce the frequency of even higher prices. Thus, the program poses a tradeoff involving a much higher probability of price at or near the ceiling, in exchange for less frequent episodes of even higher prices. ${ }^{10}$

A serious consideration for price band schemes is budget cost. There is an appealing intuition that if the mean of the floor and ceiling price equals the free-market mean, the program is 'self-liquidating', i.e. financially sustainable, based on the expectation that net balances should equal zero. It is also intuited that the summed funds from purchases and sales after several years of operation should be close to their initial values. This intuition is, however, inaccurate even for a simple floor price scheme in a market with linear demand and no underlying trend. Simulations demonstrate that over the years the balances of such programs have no tendency to cluster

\footnotetext{
${ }^{9}$ Modeling the dynamic equilibria of storable commodity markets requires use of numerical techniques for a function that links equilibrium price to available supply. Simulation of long series of random harvests is used to characterize the distribution of prices implied by model parameters. For details, see Williams and Wright (1991).

${ }^{10}$ For an example of projection of the effect of alternative storage schemes on the probability distribution of prices for a model calibrated on data from Bangladesh see Brennan (2003).
}

near zero, and will eventually expend any initial capital limit, perhaps after accumulating large surpluses. Additionally, experience since the Second World War has shown that these programs often fail within a decade or two. Recent failures (e. g. tin and wool) have shown that the largest and most catastrophic price effect of these interventions can be a severe price collapse (Bardsley 1994; Gilbert 1996; Haszler 1988). When such price stabilization programs fail, public consensus usually blames poor administration, but the fundamental problem is the appealing, but faulty, intuition about how the program functions.

Recent proposals for global price stabilization

\section{An international coordinated global food reserve}

An international coordinated global food reserve was recently proposed (von Braun et al. 2009), intended to reassure importers that exporters would supply them in time of need. The proposal is sketched as an agreement by members of a 'club' to include members of the G8+5 plus major grain exporters (e.g. Argentina, Thailand and Viet Nam), who would commit to holding specified amounts of public grain reserves in addition to those of the private sector. The public stores would be used to intervene in the spot market as directed by a 'high level technical commission' with full decision-making authority, and appointed by the club on a permanent basis. This proposal has some features common to the current security provisions of the International Energy Agency for dealing with disruptions in petroleum markets. A major, possibly insurmountable, challenge for such a commitmentreinforcing program is ensuring the participants honor their 
obligations and make their stocks available when markets are under stress. This is a serious issue since the club members include some exporters whose lack of commitment to their customers was a key factor in recent turmoil in the global grain trade.

\section{A global virtual reserve}

Another related proposal is for a global 'virtual reserve'. Nations that are members of the 'club' would commit funds amounting to US\$12-20 billion, to be provided by a highlevel technical commission for necessary operations in futures markets. However, operation of this large program in futures markets would require ready access to margin financing and could be subject to gaming by traders aware of the program's operating rules. One version of the proposed intervention characterizes it as a dynamic price-band system (von Braun et al. 2009) operated by a 'global intelligence unit' that also makes market forecasts and determines when markets are not functioning well. This unit would be part of an institution that "already has the long- and medium-term modeling infrastructure for price forecasting".

In another interpretation that more closely reflects written sketches by von Braun and Torero $(2008,2009)$ and Robles et al. (2009), the 'price band' mentioned appears to be irrelevant, and the function of the floor price is not discussed. The 'virtual reserve' would apparently adopt no long positions and hold no stocks in normal times. However, it would stand ready to take naked short positions (not backed by stocks or prospective harvests) when a price surge is detected by a global intelligence unit endowed with information about the market or special forecasting powers unavailable to other market participants. The idea is to arrange access to cash reserves to back these interventions, which "will reduce spot prices and should make speculators move out of the market" (von Braun and Torero 2009).

The intervention is thus designed to reduce levels of stocks deemed excessive by the global intelligence unit. This is a puzzling response for addressing recent price spikes which, as noted, occur only when stocks are at minimum levels relative to supplies available to the market. Nor is it clear why the 'global intelligence unit' would have superior ability to know when the market is not functioning well. Given the multibillion dollar cost estimated (von Braun and Torero 2009), these questions and other technical issues (e.g. Wright 2009) must be answered before these proposals are seriously considered as policy options.

What impact does food price have on food security?

Discussions of the recent food market crisis have naturally associated high food prices with food insecurity. However, too little attention has been paid to the nature and quantitative relationship between price level and food insecurity. The analysis has focused on price volatility and the presence of spikes, often with reference to the shortterm, intra-seasonal volatility of quoted prices.

One problem is that the official statistics on prices, as used by analysts, provide only partial information on the conditions of local food markets. Thus, if a daily or weekly high price is quoted on a mercantile exchange, with no indication of the volume traded during that period, it is difficult to assess the implications for food available or the prices for poor consumers. The high price, especially if the spike lasts only a few days or weeks, might be associated with limited transactions in a thin market; for example, as exporters restricted access to their markets in 2007-2008, the links between the welfare of their domestic consumers and prices on global markets were severed. In addition, the major importers, including most MENA countries, have long insulated much domestic consumption from global price volatility, often reducing the mean prices of domestic consumption below market levels. This indicates the limitations of inferences relating short-term volatility of prices to consumer welfare in MENA countries. Policy makers should consider whether prices should be allowed to fluctuate with the world market in future periods of market turmoil. If not, budget exposure, and the possibility of running out of stocks due to lack of financial resources or foreclosure of timely access to world markets, are major concerns.

Price stabilization proposals, as discussed above, focus on the 'global market', that part of the world market for which prices on the principal grain futures markets are most relevant. In the recent tumultuous years these prices totally differed from those faced by most consumers in developing countries (De Hoyos and Medvedev 2009). For MENA countries, stabilization of the international price is less important than, and quite distinct from, local market stability. Thus the first question for MENA countries to resolve is the objectives of policies related to stability of regional grain markets.

\section{Policy objectives of countries in the MENA region and related instruments}

Despite significant reforms, food subsidies are still prevalent in MENA countries, and impose a significant fiscal burden. They generally make larger per capita transfers to the rich rather than to the poor, giving little reason to believe that their major objective is to improve welfare of the poor. One review stated, "The resistance to radical food policy reform is $[\ldots]$ due primarily to the fear of civil unrest and its subsequent impact on political stability. Past 
experience in the MENA region illustrates the potentially explosive nature of food price increases (e.g. Tunisia, Morocco, Egypt, Jordan), substantiating the concerns of policy makers" (World Bank 1999). If long-standing policies of subsidizing grain or bread consumption are not abandoned in the near future, the relevant question changes from whether MENA governments should intervene, to how they should optimize their market stabilizing interventions, given their political constraints.

\section{National strategic reserves}

One reason that grain prices have not completely reverted from recent peaks is that many countries are rebuilding or expanding their grain reserves in reaction to the export bans and taxes observed recently. ${ }^{11}$ Thus, these countries are indicating that they do not view international futures markets as reliable substitutes for the local accumulation of stocks. This is easy to understand for landlocked African countries which rely on the transport infrastructure of neighboring countries, and are subject to foreclosure of crucial trade routes when they are most needed. Futures contracts eliminate counterparty risk with respect to performance of the futures contract, including delivery at the designated delivery point. However, for remote countries, risks related to other counterparties, including financiers, agents, transport providers, and neighboring governments remain very important and often impossible to hedge. Furthermore a futures market might be shut down or exports banned by the host country. ${ }^{12}$

In general, MENA countries are far less remote than landlocked African countries and are close to major trade routes. It is difficult to imagine that regional events specific to grain markets, such as a local export demand surge due to a drought, could preclude access to imports from afar. A more likely motivation is concern that political or military events could cut off market access. For MENA countries bordering the Persian Gulf, risks include a blockade of the Straits of Hormuz or other serious military disturbance. For the citizens of Gaza, closure of market access via Israel is a familiar hazard. For Egypt and nearby states, closure of the Suez Canal could also be disruptive to grain imports, at least in the short term. Many MENA countries may believe that crises that disrupt their food imports might also interfere with the flow of oil revenues that fund these

\footnotetext{
${ }^{11}$ Recent reports indicate that Saudi Arabia, Egypt, Iran, China, Russia, Jordan, Mozambique, Morocco and Malawi are placing grain in national reserves (Marc Sadler, personal communication, April 2009).

12 Both actions were taken in India in 2007 even though the situation in world grain markets fell far short of emergency conditions; and even the USA once briefly banned soybean exports in 1973.
}

imports, and this double exposure should loom large in their planning for food and energy security.

A national food reserve is thus an essential element of a prudent national security policy for many MENA countries. The key question, then, is the size of the reserve. The answer must depend on such facts as the diversity of food supplies, dependability of traditional suppliers, and the cost of the program. Such stocks tie up capital for the substantial intervals between releases and can be expensive to maintain (stocks are 'rolled over' with no net release, as required to maintain quality). Their efficient management also uses scarce human capital, and temptations for corruption can easily arise.

Two generalizations about MENA countries are important for the design of their emergency reserves: their extraordinary dependence, as a group, on imported grain for their food supply; and their heavy and continuing subsidization of the very grains upon which they are so dependent. The latter suggests that private competitive storage is likely to be unattractive, even in the absence of special stabilization measures. Storage is likely to be dominated by publicly controlled stocks, and perhaps by unknown quantities held by consumers against disruption of the public distribution system. The effects of public stocks on incentives for private commercial storage are likely to be less salient in the design of a public storage policy. However, the subsidies encourage excessive consumption of grain products and exacerbate dependence on their importation.

MENA countries are large importers on the international scene; however, their aggregate consumption is too small to require them to pay much attention to the effects of their policy choices on the international price, except perhaps with respect to short-term purchasing tactics. Thus, the national storage activity discussed here is appropriately directed at a stockpile of a size deemed appropriate to meet security goals efficiently, relative to alternative policies, rather than aimed at affecting prices.

The peculiar circumstances of most MENA countries extend to the nature and attractiveness of major alternatives. The region is primarily dry, and most countries, especially around the Gulf, are unpromising candidates for agricultural expansion. Where irrigation is economically feasible, as in Egypt, the comparative advantage should be in highvalue, labor-intensive agriculture rather than grain production. Nevertheless, policy documents of the Arab Economic Summit and of the Arab Organization for Agricultural Development (AOAD) still advocate expansion of grain production to enhance food security.

In this situation, a major benefit of storage as a security mechanism is to substitute for much more costly efforts to expand grain production. Saudi Arabia has recognized the folly of producing grain at a cost five times the prevailing world price, while depleting its scarce supply of fossil water 
and spreading salinity. Storing 1 or 2 years' supply in its dry desert climate, though incurring a substantial capital cost, might be a sustainable and far more economical use of its resources than its former production regime. Other MENA countries around the Mediterranean have better agricultural potential; however, at the margin, many would be better to turn to larger stockpiles rather than expansion of grain production to give them the security they seek.

MENA countries not wishing to subsidize a large portion of food consumption, but seeking to target the most vulnerable, can design effective policies that encourage participation of the private sector in their grain markets (see Wright 2009). Egypt's policy of making coarse 'baladi' bread available at a low fixed price is an example of a selftargeting strategy which limits leakage of aid to richer consumers. If public aid is restricted to bread favored only by the poor, it can leave the rest of the market to the private sector except in dire emergencies. The public distribution system can then be a major part of a strategy to 'roll over' strategic stocks, keeping them viable, while minimizing the effects of sales from stocks on the private market.

\section{A regional reserve}

To complement national strategic reserves, regionally coordinated reserves must also be considered. As suggested earlier, there is potential for smoothing out wheat availability in most MENA countries by pooling production; aggregate regional production is smoother than production in many individual countries. To the extent that regional governments can commit to maintain MENA trade access in cases of rising prices, trade within the region should stabilize local food markets up to the limits imposed by trading costs. If the objective is overall market stabilization, then the only commitment needed by regional government is not to ban food exports. Unfortunately, some exporters within the region have not fulfilled this commitmentwhen shortages loomed, their own consumers lobbied successfully to ban or tax exports (e.g. Egypt, Syria, Yemen and Iraq) (World Bank 2009).

If local shortages are unrelated to global market conditions, so that the exporter commitment problems are less relevant, a regional reserve might improve the short-term responses to local food crises. Such a reserve might alleviate recent difficulties of lags in food aid responses and mismatches between years when aid is plentiful and when it is needed. However, its operation poses many challenges familiar to administrators of aid programs. The disincentives caused by the price-depressing effects of food distribution must be minimized for local farmers and merchants who are always the first line of defense against famine for countries during serious food shortages. For example, ensuring that transport is available to promptly deliver aid may be a problem for landlocked countries. It seems likely that direct assistance to the neediest, where feasible, would be more effective than attempting to reduce prices by supplying extra grain to regular food markets. Public employment programs for those able to work have been successful when the reward for work has been kept low enough to be unattractive to those with other employment alternatives (Subbarao 2003; Del Ninno et al. 2009).

\section{Logistics considerations}

If some MENA countries (e.g. around the Mediterranean) are confident of access to world grain markets even in emergencies, they can economize by holding lower levels of precautionary stock. However, for reliable protection against shortages, they need to ensure that their needy consumers can receive imported supplies when and where needed. This is more difficult than it seems. The logistical chain for imports can look totally different when under delivery pressure. Stocks moved quickly into ports are useless if ships cannot be unloaded or supplies moved from port, due to unaccustomed congestion. Under equipment constraints, a normally comprehensive and economical rail system serving a large area with many stations can change into a system with few useable stations, as revealed in a study of the West Australian wheat market (Brennan et al. 1997). If similar comprehensive studies of emergency logistics are not available to MENA countries, they could be advantageous.

\section{Other recent proposals to address price volatility}

Besides measures affecting storage activity directly, other policies might be considered to reduce market volatility and/or increase market access - some have considerable merit, others do not, and the following starts with the more promising.

\section{Commitments to divert grains from biofuel and feed uses in emergencies}

Modern food markets are more inherently stable than their predecessors. Now, an increasing proportion of food grains and oilseeds is being used for biofuels or for animal feed. While biofuels production is unlikely to be high in the MENA region, animal feeding will rapidly increase as incomes rise. In a food supply emergency, it should be possible for MENA governments to offer contracts to animal feeders in their own countries that commit the latter to divert grains and oilseeds to food use in specified food market emergencies. Such diversion should increase food supplies when needed, and has the additional short-term benefit of increasing the supply of meat from animals that would otherwise be kept or used for breeding. 


\section{Investment in foreign agricultural land}

This strategy has been pursued mostly by oil-rich Arab countries (Gulf countries and Libya) to address long-term food security, while recognizing that self sufficiency is not an option, and in conditions of growing concern about the reliability of free international trade. However, after an initial surge, the rush towards foreign investments in land seems to be subsiding. The reduction of food prices since 2008 , the onset of the financial crisis with associated credit restrictions, ${ }^{13}$ and growing concerns about the effects of some of the announced deals on the welfare of local farmer communities, led to some deals being either delayed or abandoned. Nevertheless, there is still strong interest in investment in foreign land, with Sudan and Pakistan being the most attractive to Arab investors. Sudan is geographically wellplaced to be a long-term supplier of Gulf countries and Egypt. Currently, however, Sudan cannot feed its own population, but would definitely benefit from careful foreign agricultural investment. The fundamental obstacles to such deals may be lack of adequate infrastructure and property rights, and underdeveloped legal systems in the countries involved.

\section{Commitments to refrain from using export restrictions}

Recent experience in the rice market has demonstrated the hazards of reliance on imports to satisfy needs for a staple commodity. Exporters and importers have a joint interest in maintaining trade when prices are high, both reaping the full benefits of the smoothing role of trade, which can exceed what can be achieved via storage. However, commitments of governments beyond the terms of the current administrations are difficult to achieve and can easily collapse under pressure from politically powerful urban consumers. One useful policy change to improve the commitment capacity of exporters is to reform WTO disciplines on export bans and taxes consistent with existing rules against import tariffs and quotas. However, some observers note that such a discipline would have little power in an emergency, as WTO sanctions do not apply retrospectively.

\section{Oil-for-food arrangements}

The UAE, presumably capable of offering a logical foodfor-oil deal, could not obtain blanket assurances from Pakistan not to apply export controls on grain produced from the UAE's planned agricultural projects in that country (Anon. 2009). However, such projects should be

\footnotetext{
${ }^{13}$ At the 5th World Islamic Economic Forum in March 2009, for example, the Binladin Group decided to delay its plan to invest $\$ 4.3$ billion in rice production in Indonesia as a result of the global financial crisis (Smaller and Mann 2009).
}

possible as 'oil for food' exchanges that increase security of both parties. Similar deals might induce biofuel-producing countries to divert grain to human use in emergencies, if promised compensation of oil from a MENA source.

\section{Conditional trade agreements: food for water}

In the context of water-scarce Arab countries, the recent soaring prices of cereal grains exacerbate problems of water scarcity - such high prices clearly create incentives to produce and export irrigated crops.

The case of Syria and Turkey is interesting, where for years they have been negotiating the distribution of the water flows of rivers originating in Turkey and flowing through Syria. The major issue is the Euphrates, on which an agreement exists, whereby Turkey should guarantee a flow of $500 \mathrm{~m}^{3} / \mathrm{s}$ at the Syrian border (Varela-Ortega and Sagardoy 2001, 2003). Recent droughts, however, have repeatedly revealed incompleteness and weakness in the agreement. When the Euphrates basin has received less-than average inflows, especially in summer, Turkey has reduced the water flow to Syria, claiming the agreement ought to be based on average annual flow, while Syria maintains that $500 \mathrm{~m}^{3} / \mathrm{s}$ should be the minimum guaranteed flow.

Negotiations are proceeding, apparently with no explicit link ever made with the type and volumes of commodity trade between the two countries. This situation is interesting in that water and grain trade agreements could be combined in a risk-sharing arrangement with mutual advantages for both countries. The essential elements of one possible conditional trade agreement are reported in the box below. By being creative and focusing on the real issues at stake, mechanisms like the one envisaged would allocate water to the best user, and will prevent water being 'wasted' in Turkey when it would be socially very valuable in Syria.

\section{Conclusions}

The storability of grains causes the price response to a change in supply to vary with the level of available supply. The major grains - wheat, rice and maize - are substitutable in the global market for calories. When their aggregate supply is high, a modest reduction can be tolerated with a moderate price increase by drawing on discretionary stocks. However, when stocks decline to a minimum feasible level, price becomes much more sensitive to small shocks. In a free market, high prices may force poor consumers to spend much of their resources on food and reduce consumption, at great personal cost. Others reduce consumption very little, even when prices soar.

In 2007-2008, the aggregate stocks of major grains carried over from the previous year were at minimal levels 
due largely to the substantial mandated diversions of grain and oilseeds for biofuel and the strong and sustained increases in income in China and India. Lack of stocks rendered the markets vulnerable to modest but unpredictable disturbances, such as regional weather problems, the further boost to biofuel demand from the oil price spike in 2007-2008, the unprecedented extension of the Australian drought, and other production problems. However, supplies in the market were sufficient to meet food demands without any price jumps had exporters not panicked, leading to a cascade of export bans and taxes that cut off importers from their usual suppliers.

These recent events have, understandably, forced MENA countries to focus on their vulnerability to the continued turmoil in grain markets. In deciding the best policies to adopt, each country must carefully consider its definition of adequate food security, given its resource endowments and the tradeoffs from different policy options.

In general, accumulation of stocks is a more effective and much cheaper strategy than attempting grain self-sufficiency.

Additionally, investment in foreign land for grain production is unlikely to solve the problem of unreliability of access to imports in emergencies, manifest in the actions of many exporters in recent years.

Finally, countries should seriously consider whether a policy that substantially subsidizes grain consumption, even for wealthy citizens, and discourages control of waste and diversification of calorie sources, is worth its price in terms of budget expense and a greater dependence on foreign supplies of one or two grains.

Open Access This article is distributed under the terms of the Creative Commons Attribution Noncommercial License which permits any noncommercial use, distribution, and reproduction in any medium, provided the original author(s) and source are credited.

\section{Appendix}

Elements of a possible grain-for-water agreement between Syria and Turkey

The essential elements of a possible conditional trade agreement between Syria and Turkey are as follows. At the beginning of the season, Turkey transfers $X$ t of wheat (barley, sorghum, millet or any combination) to Syria. During the season, the water flow at the Turkey-Syria border is monitored. If the flow is reduced below $Y \mathrm{~m}^{3} / \mathrm{s}$ for a total of $N$ or more days during the season, Syria is entitled to keep the stock of grains without payment to Turkey. However, if the flow remains above this minimum, Syria pays Turkey the average world price of wheat, gross of interests accrued and, possibly, a risk premium. The wheat transferred from Turkey to Syria acts as 'collateral' paid by Turkey to guarantee Syria that it will adhere to the agreed minimum flow of water. Further it ensures that water for wheat production will be used primarily in the country where that is done most efficiently. The model assumes that:

(a) in 'normal' years, the water released to guarantee the minimum flow has a zero opportunity cost for Turkey (the parameter $X$ can always be defined in such a way that this condition is true);

(b) in 'normal' years, and without policy distortions, Turkey would export and Syria would import wheat (i.e. it is assumed that Turkey holds a comparative advantage in wheat production compared to Syria).

The agreement would specify the parameters $X, Y$ and $N$ to a mutual advantage, which will surely exist, given the contract structure, given a difference in the marginal value of water in the two countries. This point is explained in the following. In normal years, there will be no loss to either party by maintaining the minimum flow: only establishing a regular wheat trade from Turkey to Syria. In a drought year, Turkey might find it convenient to reduce the water below the minimum guaranteed flow only if the shadow value of water in wheat production in Turkey is so high as to justify foregoing the returns on the wheat stock used as 'collateral'. If the value of water in Turkey, even in a drought year, is lower than in Syria, it will be convenient for Turkey to 'sell' the marginal water to Syria and not forego the payment for the collateral wheat. In contrast, if Turkey decides to keep the water, Syria will have the minimum stocks needed to guarantee their food security, and procured at minimal cost.

The structure of incentives of such an agreement depends on the relative value of water in the two countries, and so on their respective rainfalls. Syria currently uses most of its water to produce wheat and cotton, and with problems in current irrigation practices, water consumption is high. Thus, the amount of wheat-equivalent as a guarantee against the water deficit might be sensibly lower than what Turkey might be losing in guaranteeing the agreed minimum flow of water. Syria will face the risk that the grain price increases during a drought and yet Turkey fulfills the minimum guaranteed flow, but this risk could be relatively easily hedged on global markets by trading wheat futures.

\section{References}

Abbott, P. C., Hurt, C., \& Tyner, W. E. (2008). What's driving food prices? March 2008 update. Oak Brook: The Farm Foundation.

Abbott, P. C., Hurt, C., \& Tyner, W. E. (2009). What's driving food prices? March 2009 update. Oak Brook: The Farm Foundation. 
Anonymous (2009). Global strategic analysis. Oxford Analytica, 20 April 2009. London: Oxford Analytica.

Bardsley, P. (1994). The collapse of the Australian wool reserve price scheme. Economics Journal, 104, 1087-1105.

Bobenrieth, E. S. A., \& Wright, B. D. (2009). The food price crisis of 2007/2008: Evidence and implications. Paper presented at the Joint Meeting of the Intergovernmental Group on Oilseeds, Oils and Fats (30th Session), the Intergovernmental Group on Grains (32nd Session) and the Intergovernmental Group on Rice (43rd Session), Santiago, Chile. 4-6 November 2009.

Bobenrieth, E. S. A., Bobenrieth, J. R. A., \& Wright, B. D. (2004). A model of supply of storage. Economic development and Cultural Change, 52(3), 605-616.

Brennan, D. (2003). Price dynamics in the Bangladesh rice market: implications for public intervention. Agricultural Economics, 29, $15-25$.

Brennan, D., Williams, J. C., \& Wright, B. D. (1997). Convenience yield without the convenience: a spatial-temporal interpretation of storage under backwardation. Economics Journal, 107(443), 1009-1022.

Cafiero, C., Bobenrieth, E. S. A., Bobenrieth, J. R. A., \& Wright, B. D. (2009). The empirical relevance of the competitive storage model. Journal of Econometrics. doi:10.1016/j.jeconom.2009.10.008. Accessed 10 November 2009.

De Hoyos, R. E., \& Medvedev, D. (2009). Poverty effects of higher food prices. A global perspective. Policy Research Working Paper 4887. Washington: The World Bank.

Del Ninno, C., Subbarao. K., \& Milazzo, A. (2009). How to make public works work: a review of the experiences. Social Protection Discussion Paper 0905. Washington: The World Bank.

Gilbert, C. L. (1996). International commodity agreements: an obituary notice. World Development, 24(1), 1-19.

Gilbert, C. L. (2008). How to understand high food prices. No 823, Department of Economics Working Paper No. 823. Trento: University of Trento.

Haszler, H. C. (1988). Australia's wool policy debacle: Efficiency, equity and government failure. $\mathrm{PhD}$ thesis. Victoria: La Trobe University.

Hater, R. (2008). Impacts of the utilization of agricultural crops in biofuels production on the Arab and world food security. Presented at the Training Workshop on Food Security Policies in the Arab Countries under the World Food Crisis. National Agricultural Policy Center, Damascus, Syria, 3-7 August 2008.

Houthakker, H. S. (1967). Economic policy for the farm sector. Washington: American Enterprise Institute.

Jopson, B., \& Blas, J. (2008). Ethiopian exchange bans trading in futures. Financial Times, 20 April 2008. London: Financial Times.

Keynes, J. M. (1942). The international regulation of primary products. In D. Moggridge (Ed.), Collected writings of J. M. Keynes, volume 27, 1982. London: Macmillan.

Mitchell, D. O. (2008). A note on rising world food prices. Policy Working Paper 4682. Washington: The World Bank.

Newbery, D. M. G., \& Stiglitz, J. E. (1981). The theory of commodity price stabilization: A study in the economics of risk. Oxford: Clarendon.

Paul, A. B. (1970). The pricing of binspace: a contribution to the theory of storage. American Journal of Agricultural Economics, $52(1), 1-12$.

Roberts, M. J., \& Schlenker, W. (2009). World supply and demand of food commodity calories. American Journal of Agricultural Economics, 91(5), 1235-1242.

Robles, M., Torero, M., \& von Braun, J. (2009). When speculation matters. Issue Brief 57. Washington: International Food Policy Research Institute.

Slayton, T. (2009). Rice price forensics: How Asian governments carelessly set the world rice market on fire. Working Paper 163. Washington: Center for Global Development.
Smaller, C., \& Mann, H. (2009). A thirst for distant lands: Foreign investment in agricultural land and water. Winipeg: International Institute for Sustainable Development.

Subbarao, K. (2003). Systemic shocks and social protection: Role and effectiveness of public works programs. Washington: The World Bank.

Timmer, C. P. (2008). Causes of high food prices. Asian development outlook update. Manila: Asian development Bank.

Varela-Ortega, C., \& Sagardoy, J. A. (2001). Final report on agricultural water use. Damascus: National Agricultural Policy Center.

Varela-Ortega, C., \& Sagardoy, J. A. (2003). Irrigation water policies in Syria: Current developments and future options. In C. Fiorillo \& J. Verqueil (Eds.), Syrian agriculture at the crossroad. Agricultural Policy and Economic Development Series No. 8. Rome: Food and Agriculture Organization of the United Nations.

von Braun, J., \& Torero, M. (2008). Physical and virtual international food security reserves to protect the poor and prevent market failure. Policy Brief 4. Washington: International Food Policy Research Institute.

von Braun, J., \& Torero, M. (2009). Implementing physical and virtual food reserves to protect the poor and prevent market failure. Policy Brief 10. Washington: International Food Policy Research Institute.

von Braun, J., Lin, J., \& Torero, M. (2009). Eliminating drastic food price spikes $-A$ three pronged approach. Washington: International Food Policy Research Institute.

Williams, J. C., \& Wright, B. D. (1991). Storage and commodity markets. Cambridge: Cambridge University Press.

World Bank (1999). Consumer food subsidy programs in the MENA region. Middle East and North Africa Region Report 19561MNA. Washington: The World Bank.

World Bank (2009). Improving food security in Arab countries. A joint report by FAO, IFAD and the World Bank. Washington: The World Bank.

Wright, B. D. (2009). International grain reserves and other instruments to address volatility in grain markets. Technical background paper, the World Grain Forum 2009. St. Petersburg, Russia. 6-7 June.

Wright, B. D., \& Williams, J. C. (1982). The roles of public and private storage in managing oil import distributions. Bell Journal of Economics, 13, 341-353.

Yemtsov, R. (2008). The food crisis: Global perspectives and impact on $M E N A$, fiscal and poverty impact. Washington: The World Bank.

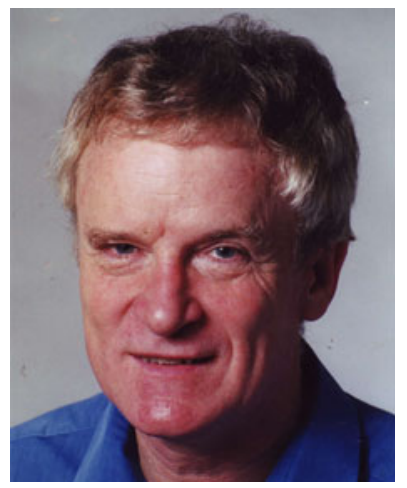

Brian Wright's interests in economics uncertainty and innovation date from his early experiences on his family's sheep station in the Riverina district of New South Wales, Australia. He received a Bachelor of Agricultural Economics from the University of New England, Armidale; and an A.M. and Ph.D. in Economics from Harvard University. He then joined Yale University's Economics Department and is now Professor of Agricultural and Resource Economics at the University of California, Berkeley. His research interests include economics of markets for storable commodities, market stabilization, agricultural policy, industrial organization, public finance, invention incentives, intellectual property rights, the economics of research and development, and the economics of conservation and innovation of genetic resources. He has published extensively, and co-authored or co-edited several books. 


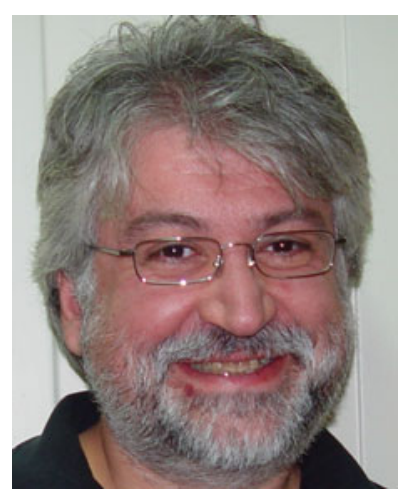

Carlo Cafiero has been a ricercatore confermato at the Dipartimento di Economia e Politica Agraria of the Università degli Studi di Napoli Federico II, Italy, since November 2003. He is also a senior research associate at the Centro per la Formazione in Economia e Politica dello Sviluppo Rurale in Portici, Italy.

After graduating from the University of Naples, he obtained two Masters degrees (one from the Centro di Specializzazione e Ricerche Economico Agrarie per il Mezzogiorno, in Italy, and one from the University of Arizona) and two doctoral degrees: a Dottorato di Ricerca in Agricultural Economics and Policy from the Università degli Studi di Napoli Federico II, and a PhD in Agricultural and Natural Resource Economics from the University of California at Berkeley, in 2002.

Since 2002, he has consulted extensively for International Organizations such as FAO, the World Bank the European Commission and the European Parliament, and with the Italian Ministry of Agricultural, Food and Forest Policies.

He currently teaches Agricultural Economics and Policy at the undergraduate level, and Applied Econometrics and Statistics at the graduate level and he is member of the teaching board of the Doctoral School of the College of Agriculture of the University of Naples Federico II.

His research interests include the econometrics of commodity markets, the analysis of risk management in agriculture, agricultural policies in developing countries, and the methodology of scientific research in economics. His dissertation work has led to an innovative publication on the estimation of the Competitive Storage Model. He has published in Italian and International refereed Journals on policies for risk management in Agriculture, and co-edited a volume on Farm Income Stabilization Policies. 